\title{
DE ISLAS Y UTOPÍAS EN LA LITERATURA ARGENTINA*
}

\author{
Mónica Bueno* $^{* *}$
}

\begin{abstract}
Resumen: La literatura argentina posee gran diversidad de islas que hacen un mapa singular de la geografía de la ficción y apuntan a conformar distintas politicas en la relación de la ficción con la literatura y de la literatura con la vida. Si estas ficciones geográficas pueden leerse como construcciones conceptuales que entraman lo posible en lo ficticio, pretendemos presentar, en este articulo, tres modelos que traban la relación entre ficción y utopia de manera diferente pero que, en todos los casos, apuestan a una política de la literatura.
\end{abstract}

Lo que puedo dar os doy, que es una instla, hecha y derecha, redonda y bien proporcionada, y sobremanera fértil y abundosa, donde si vos os sabéis dar maña, podéis con las riquezas de la tierra granjear las del cielo. (El ingenioso hidalgo Don Quijote de La Mancha, Miguel de Cervantes)

La metáfora de la isla funciona casi emblemáticamente en la literatura porque por un lado, remite a una tradición que arma la serie de la novela de aventuras y por otro, abre una línea que tiene su origen en la Utopía de Tomás Moro. Esta metáfora se construye con una figura geográfica que se define como una porción pequeña de tierra limitada por agua. Es común escuchar que muchos de aquéllos que visitan una isla sufren el síndrome de la claustrofobia, o por lo menos, un

- Recebido para publicação em junho de 2007.

- Professora Lic. Universidad Nacional de Mar del Plata. 
ligero malestar por la certeza de la incomunicación. La clausura es una de las notas características de la isla pero que también conforma la de la utopía. La historia de Moro tiene como estructura básica la llegada de un Viajero perdido a la isla, el descubrimiento de una sociedad diferente que trabaja con el principio del revés y el regreso, para poder contar lo visto. El relato de la experiencia perdida del que se lamenta Walter Benjamin Ficción y relato, los dos principios de la literatura, se muestran en el marco de la utopía. Si la fictio, como decía Platón, consiste en que una cosa que no es sea, en los relatos sobre la isla que lo que no es se potencia de tal manera que permite el juego de las virtualidades. La isla es el lugar de lo otro que además es lejano e inalcanzable. Se hace importante entonces la figura del narrador que puede recorrer el tránsito entre los dos espacios y contarlo. Utopía y ficción encuentran en la isla el diseño apropiado para reconocerse ya que la utopía es una isla por voluntad humana (su fundador Utopos ha cortado el brazo de la tierra que lo ligaba al continente), por lo tanto, esta demarcación precisa y buscada define los límites del mundo de ficción.

La literatura argentina posee gran diversidad de islas que hacen un mapa singular de la geografía de la ficción ${ }^{1}$ y apuntan a conformar distintas políticas en la relación de la ficción con la literatura y de la literatura con la vida. Si estas ficciones geográficas pueden leerse como construcciones conceptuales que entraman lo posible en lo ficticio, pretendemos presentar tres modelos que traban la relación

1 La idea de mapa nos surge del libro de Alberto Manguel y Gianni Gaudalupi Guía de los lugares imaginarios publicada por Alianza en 1992. En el Prólogo, Manguel relata que el libro comenzó a escribirse una tarde de 1977, cuando los dos autores intentaron orientar a los viajeros por los laberintos de Selene, la ciudad vampiro de Pautl Féval. Surgió la idea de componer así un diccionario turístico de lugares ficcionales. 
entre ficción y utopía de manera diferente pero que. en todos los casos, apuestan a una política de la literatura.

\section{LA INVENCIÓN DE MOREL: PRIMERA ISLA DEL MAPA}

Si se le pregunta a cualquier lector sobre islas en la literatura argentina, rápidamente mencionará la novela de Bioy Casares. La invención de Morel trabaja con los principios clásicos que mencionáramos antes de la novela de aventuras y de la utopía. ${ }^{2}$

Dejémoslo al autor resumir la trama: "Me parece casi un milagro que se me haya ocurrido una historia en la que un fugitivo que va en un bote y llega a una isla que parece despoblada, se queda dormido y a la mañana siguiente de ese día, en esa isla remota y desierta, lo despierta la música de Té para dos."(RUSSO, M y RIERA, 1996, p. 12) En esta historia fácilmente reconocible para cualquier lector de novelas de aventuras, de utopías, Bioy inscribe la marca de la diferencia que hace operar en el entramado ficcional. La isla del fugitivo solitario empieza a poblarse de amables y virtuales personajes que repiten incansablemente sus jornadas. En la isla, hay también una casa en la colina, y, en la casa, una máquina que

2 La relación y vecindad entre la utopía y el relato de viajes ha sido estudiada por diversos investigadores. Al respecto señala Moreau, uno de los especialistas en el tema: "La utopía roza todos esos géneros [viaje imaginario, viaje satírico, mito, ciudad ideal restauradora], a tal punto que, a veces, se ha podido declararlos indiferenciables. Sin embargo, es preciso intentar diferenciarlos, porque sólo trazando rigurosamente las líneas de demarcación que la separan de sus vecinos, como se han trazado las que la separan de sus "ancestros" nos aproximaremos con la mayor exactitud posible al hecho esencial de la utopía." Bioy hibrida los dispositivos diferenciadores de los que habla Moreau y desordena la información por lo tanto, apunta a una mayor entropía. Cfr. Pierre-Francois Moreau, La utopía. Derecho natural y novela del Estado. Buenos Aires: Hachette. 1986.101. 
fábrica imágenes para la inmortalidad que un científico, Morel, ha creado, y que el azar ha puesto en marcha.

El juego se arma en la lectura que el náufrago hace de la realidad. Transformado en detective e investigador, ensaya diversas interpretaciones de lo que le toca vivir, sin acertar con ninguna de ellas. Una pesquisa minuciosa será la que marcará toda la segunda parte del relato. Las pistas que el narrador descubre nos las ofrece para que también realicemos nuestros propios ensayos de interpretación. Pronto, el narrador se da cuenta de que ni lo ven ni lo oyen. Su estupor se agranda al enamorarse de una de esas representaciones, Faustine. Las hipótesis acerca de la ignorancia del grupo frente al extraño se multiplican y van siendo anuladas hasta llegar al descubrimiento de la máquina. Finalmente, ante el develamiento del enigma (todos están muertos pero la máquina les permite el simulacro de la vida) el fugitivo toma la decisión de proyectar repetidamente las escenas de la mujer para grabar su imagen junto con la de ella. De esta manera, no sólo inventa un recuerdo que no existió, hace virtual una realidad imposible (cuando llega a la isla, Faustine ya está muerta) sino que también firma su sentencia de muerte.

Bioy ha dicho en varios reportajes que le gustaría morir frente a una pantalla de cine, pero, confiesa, que firmaría un contrato, sin leer las cláusulas, que le otorgara la inmortalidad. Esta novela apela a la posibilidad de imágenes inmortales construidas gracias a la ciencia y la técnica. El inventor de extraños aparatos, tipo cultural de los años veinte (basta recordar los inventos de Roberto Arlt), es exacerbado en función de la gran máquina de ilusiones: el cine. Morel, este científico loco que crea la máquina que fija las imágenes haciéndolas eternas, inventa un mundo de ficción que el náufrago registrará en su Diario, en un principio, como real. 
Es así que se presentan universos aparentemente cerrados. que funcionan con un menor grado de entropía. El universo armado por Morel, el universo armado por la intromisión del náufrago y su enamoramiento de Faustine, el universo de la escritura del Diario y las notas a pie de página del Editor con su afán interpretativo y corrector $\mathrm{y}$, finalmente, el universo del lector. Estos universos, que aisladamente presuponen procesos de alto grado de reversibilidad, al superponerse por la sintaxis del relato se encadenan abriéndose cada universo en función. del otro. Se arma entonces un sistema altamente permeable a la imprevisibilidad y que hace el proceso, irreversible. Desde la figura de Morel a la figura del lector se construye esa suerte de espejos que, si bien, se multiplican, establecen, en cada repetición, el signo de la diferencia.

La máquina de Morel fracasa no por la imperfección de su mecanismo sino porque, en la copresencia de todas las posibilidades que ofrece, se agrieta por lo inesperado, en este caso, la aparición del náufrago. Leído desde otro punto de vista, la máquina crea el artificio del sistema perfecto, cerrado, reversible, sin embargo, su autosuficiencia se ve quebrada por la entrada de un elemento del universo que no es previsible. De todas maneras, la saturación del proceso se evidencia en su irreversibilidad y esta irreversibilidad se efectúa en la escritura y la publicación del Diario, que implica el final de la clausura del intento utópico.

La crítica en general ha coincidido que tanto esta novela de 1940 como Plan de evasión poseen un soporte científico que se basa sobre textos de divulgación. Tal es el caso de An experiment with time (1927) del ingeniero británico aeronáutico John William Dunne. Pero además recoge la tradición literaria anglosajona pródiga en utopías, en islas alternativas y clausuradas desde Moro en adelante, pasando 
por Wells y su La isla del doctor Moreau. Esta tradición utópica que parte del Renacimiento (Moro, Campanella y Bacon) marca la concreción de ficciones que operan como mundos alternativos que tienen como notas características la clausura y la diferencia. Bioy hace jugar un relato que arma con dos historias paralelas, dos series de acontecimientos que no se cruzan pero que ocupan el mismo espacio de la isla, lugar de la utopía ${ }^{3}$. Mientras el viajero de Moro, llega a Utopía y reconoce, en la experiencia cotidiana, las marcas de la diferencia (otro lenguaje, otros códigos sociales, otra arquitectura urbana), el viajero de Bioy no encuentra la desemejanza en estos códigos de relaciones interpersonales sino, paradójicamente, en la ausencia de ellos. Si el lector reconoce las marcas de una tradición en ciertos elementos (la isla solitaria, el viajero y el encuentro con lo diferente), este reconocimiento pronto empieza a trastabillar pues ni la isla se transforma en un mundo alternativo, ni sus habitantes conforman una sociedad distinta ni el viajero contrasta ese mundo hecho de otros códigos con el suyo propio abandonado. Con un guiño, Bioy apuesta al aumento de la entropía en la experiencia literaria del lector y agrega un elemento más: después de asistir a las perfectas repeticiones de las secuencias semanales y olvidado ya, del resguardo por ocultarse, descubre que mientras él se siente absolutamente atraído por Faustine (femenino de Faustọ), ni ella ni los otros habitantes parecen registrarlo. El mito fáustico que recoge otra tradición, la romántica, y que evidencia la preocupación humana por vencer la muerte y el deterioro, (preocupación que como vimos el mismo Bioy comparte) pone

3 A propósito, Blas Matamoro realiza un recorrido sumamente interesante por las "muchas islas del mundo de la fábula" hasta llegar a la de Morel. Cfr. Blas Matamoro, "Archipiélago" en Adolfo Bioy Casares, Premio "Miguel Cervantes" 1990. Barcelona: Editorial Anthropos/ Ministerio de Cultura, 1991.81 a 95. 
en alerta, la lectura. Este no-lugar, trabaja la zona intermedia donde la vida y la muerte parecen rozarse. Se trata de una forma alternativa al fin, pero no como crítica política, o como sociedad imaginativa perfectible para un futuro real sino como metáfora de las máquinas que crean ilusiones, simulacros que virtualmente vencen a la muerte. La máquina funciona también como metáfora de la literatura, que se activa para contar historias, para crear mundos posibles, que se tornan reales por la vívida comunicación que se establece entre lector y el texto. Los personajes de Morel son eternos gracias a no estar vivos porque la vida es un proceso irreversible que tiene en ese alto grado de entropía su mayor riqueza, y también su terrible agonía. Sin embargo, el párrafo final de la novela apuesta a ciertas formas de la eternidad que el hombre ha intentado desde siempre: la del amor, la del arte. La súplica del enamorado a un inventor posible que continúe la máquina de Morel, puede leerse también como el pedido a un eventual lector que subvierta su lugar y prosiga las invenciones de la ficción. Este último gesto desordena también los roles que la institución literaria fija. ${ }^{4}$

Sergio Cueto analiza con acierto los rasgos del malentendido que "acaso constituye el secreto de la relación amorosa" y que funcionan alegóricamente en la novela de Bioy. El axioma quevediano de "amor constante más allá de la muerte" se resemantiza en la máquina de Morel: "Por eso al final el narrador se filma, lleva su amor hasta la muerte, hasta más allá de la muerte, como si en esa transgresión se abriera la infinitud de amar". Cfr. Sergio Cueto "Discurso sobre el amor (al margen de La invención de Morel)", Paradoxn Año X/ No 8, Rosario: Beatriz Viterbo Editora, 1996, 7 a 12.

El inventor de una máquina que vence a la muerte es una imagen que resume con acierto el impulso vital del hombre frente a la certeza del fin. Excúsenme la anécdota pero no puede dejar de recordar que mi hijo menor, Nicolás de cinco años, hace aproximadamente un año se despertó una mañana con la seguridad de que él podría construir "una máquina que volviera el tiempo para atrás". De esta manera, sus abuelos, sus padres y aun aquéllos que él no había conocido pero que la tradición familiar le cuenta estarían "vivos para siempre". Le contesté que tal vez eso fuera posible y le conté la novela de Bioy. Me dijo que esa máquina no servía porque de esa manera "no se podía pedir nada a esas personas". 


\section{LA TEORÍA DELOS NUDOS BLANCOS: LA ISLA DE LOS LENGUAJES}

Ficción y teoría parecen términos opuestos o no conciliables en el mismo espacio de escritura. La novela en este siglo ha roto con este supuesto y ha llevado la teoría a la ficción y ha ficcionalizado teorías en el marco de la novela. Ricardo Piglia es uno de los escritores en la Argentina que ha tratado de recorrer esta relación desde su primera novela Respiración artificial en donde, desde Tinanianova Wittgenstein, los traslados se hacen evidentes y la estrategia de la erudición encierra estas postulaciones teóricas ficcionales que llevan indefectiblemente el estigma borgeano.

En diferentes entrevistas, en sus trabajos críticos, Piglia ha sostenido una política de la literatura frente al Estado. Esta resignificación del mito sartreano está matizada con la Filosofía del lenguaje que le permite construir, en la ficción, la idea de un lenguaje que subvierte. Lo ha dicho hasta el cansancio y lo ha llevado a la práctica: no es sólo su preferencia por personajes ubicados en el margen, no es sólo su reiterada fascinación por las locas pitonisas, se trata de un ejercicio que se hace militancia. Interrogado sobre la especificidad de la ficción: Piglia responde "me interesa trabajar esa zona indeterminada donde se cruzan la ficción con la verdad" y agrega "las Argentina de estos años es un buen lugar para ver hasta qué punto el discurso del poder adquiere a menudo la forma de una ficción criminal" ${ }^{\prime \prime}$. Frente a este lenguaje que enmascara la verdad, la literatura resulta para el escritor un lugar revulsivo, contraideológico que en las construcciones ficcionales encierra las formas de lo posible ${ }^{5}$ (PIGLIA, 1993:

5 Completamos la cita: "...no hay campo propio de la ficción. De hecho todo se puede ficcionalizar. La ficción trabaja con la creencia y en este sentido conduce a la ideología, a los modelos convencionales de realidad"(OP.CIT, p. 17) 
p. 17) Como Scherezade la literatura resiste las leyes del, poder.

Pensar mundos alternativos es privilegio de la Filosofía, llevarlos a la práctica, obligación social de la Historia, relatar sus extravagancias y diferencias, fundamento de la literatura. Si Morel crea una máquina en una isla para vencer la muerte, La ciudad ausente es una novela-máquina y formula, en esa paradoja, la sintaxis de la modernidad. Dónde empieza el relato de la ficción y dónde están sus límites son preguntas impertinentes en la sintaxis del mundo creado en la paranoia de una ciudad que no está pero que se muestra en los relatos.

Contar es un privilegio que todos aspiramos a tener, un privilegio que atrae la atención de los otros. En La ciudad ausente muchos relatos se pierden, se fragmentan, se esfuman porque la máquina no puede parar. El relato de la isla es uno de los últimos que formula. (Piglia publica este relato como uno de los Cuentos morales en 1997) Si en "Tlön Uqbar Orbis Tertius", el famoso cuento de Borges, la metafísica es una rama de la literatura fantástica, en la isla de Finnegans, la lingüística es la religión ominosa, la ciencia omnipresente. Una teoría del lenguaje encierra una teoría sobre la formas de vida. Desde Wittgenstein lo sabemos. En esa isla, la multiplicidad de formas vida se da en la superposición de lenguajes. Si un hombre y una mujer se aman en una lengua, se odian en otra. La ficción de la isla anula la brecha entre lo posible y lo imposible porque todas las posibilidades coexisten por la simple efectuación de la lengua. Utopía de la anulación de la univocidad de lo real, política de la ficción frente al lenguaje del Estado. Las coordenadas del tiempo y el espacio se anulan mutuamente por la superposición de lenguajes. Los lenguajes siempre están aunque sean restos o vestigios del pasado. En las lenguas exiliadas, cifradas o perdidas se encuentran, para Piglia, las fisuras del discurso que acota lo real. 
La isla de Morel construye ficción de una imposibilidad científica basada en un invento real: el cine, la isla de Finnegans ingresa en el terreno de la imposibilidad lógica. "Si el hombre posee una capacidad innata para crear símbolos" dice Wittgenstein "sin tener la mínima idea de lo que significa cada palabra" en la isla la proliferación de esta posibilidad se exacerba. De esta manera, la imagen de la realidad como un edificio sólido se desvanece.

"Dicen lo que quieren y lo vuelven a decir, pero ni sueñan que a lo largo de los años han usado cerca de siete lenguas para reírse del mismo chiste". La realidad de.la isla, decíamos es difusa e inestable porque inestable es el lenguaje que la nombra. La distorsión de las lenguas es la distorsión del tiempo y del espacio y la irregularidad de una ciudad que muta y siempre se define por lo que ha dejado de ser. En la isla, esta ciudad ausente es casi como un secreto. Los ritos de los hombres quieren recuperarla y con ella, el sentido primero, el sentido de patria. ${ }^{6}$ Es en este punto cuando el texto deja ver su dimensión utópica: despierta detrás del desideratum la anticipación de lo que todavía no ha llegado a ser. La imposibilidad lógica se vuelve posibilidad utópica porque muestra los contenidos no aparecidos y también los no decididos. Dice Ernst Bloch: "No hay realismo que merezca tal nombre si prescinde de éste, el más intenso elemento de la realidad en tanto que inacabada. Sólo la utopía socialmente lograda puede dar precisión a aquella pre-apariencia en el arte" (BLOCH, E., 1977, p. 22)

6 "Si llega a captarse asi y si llega a fundamentar lo suyo, sin enajenación ni alienación, en una democracia real, surgirá en el mundo algo que a todos nos ha brillado ante los ojos en la infancia, pero donde nadie ha estado todavía: patria". Esta afirmación a un tiempo, utópica y poética, no es de la novela de Piglia, pero podría serlo. Se trata de Ernst Bloch que postula su utopía social. (BLOCH, 1977, p. 23). 
Esta pre-aparencia en el arte a la que se refiere Bloch es la que sustenta la política de la ficción que Piglia esgrime. Política de los lenguajes que agrietan, exploran y continuamente redefinen lo real, trabajando el complot dentro de la institución literaria. Un compromiso político es para Piglia un compromiso con la ficción. Si la literatura es un no lugar productivo de todas las posibilidades -las deseadas y las necesarias - el escritor exaspera las formas de buscarlas. "El mejor de los mundos posibles" debe tener un lenguaje; todos los mundos posibles pueden tener todos los lenguajes.

Esta ficción que nos propone la isla funciona, como decíamos antes, con el presupuesto de la imposibilidad lógica. Si una de las marcas características de la utopía es la diferencia y esa diferencia se pone en evidencia en la formulación de un lenguaje, la isla de Piglia establece la diferencia por exasperación del absurdo de la mutación existente en todo lenguaje. Por otra parte, Piglia ha puesto a prueba la relación de la utopía con la ficción en Respiración Artificial y, por supuesto, ha elaborado una teoría. ${ }^{7}$ La diferencia se muestra sobre todo en la construcción de un lenguaje que anula la lógica de la retórica del poder. En la serie utópica Gabriel de Foigny es el que llega más lejos en la descripción de ese lenguaje ${ }^{8}$. Como

7 Transcribimos el fragmento de la novela: "Ahora bien, he pensado hoy: ¿Qué es la utopía? ¿El lugar perfecto? No se trata de eso. Antes que nada, para mí el exilio es la utopía. No hay tal hugar" dice Osorio. Y más adelante aclara: "La utopía de un soñador moderno debe diferenciarse de las reglas clásicas del género en un punto esencial: negarse a reconstruir un espacio inexistente". Osorio decide colocar la utopía en el tiempo porque como hombre del siglo XIX desecha la alternativa en el espacio para apostar al desafío del tiempo futuro. Lo sabemos "las utopías tienen horarios" (Bloch). Lo sabe Piglia que en La ciudad ausente retoma la idea que descarta Osorio y construye la isla. Cfr. Respiración Artificial. Buenos Aires: Seix Barral , 1994. p. 77-79.

8 Pierre-Francois Moreau en La utopia. Derecho natural y novela del Estado, señala que Gabriel de Foigny en su Tierra Austral inventa un lenguaje que 
Borges en Tlön, como Foigny, en su utopía, Piglia describe un sistema lingüístico que se basa en la simultaneidad, la pérdida y la memoria. En la descripción de ese complejo sistema está la clave de la crítica política que toda utopía despliega, está el complot que desde la literatura las ficciones organizan para desenmascarar las otras ficciones que desde el poder, desde el Estado, se cuentan como verdaderas. Los nudos blancos de la ficción existen en ese entramado lingüístico que Piglia ensaya con la metáfora de la isla; esos nudos apretados se instalan en la estrecha marca de sus lazos para escribir el libro del mundo desde el lenguaje que lo nombra y que siempre es una lengua cifrada $a^{9}$. Thomas Pavel nos propone una distinción interesante entre los mundos de ficción que la literatura nos ofrece: aquéllos que se postulan como bases de ida y vuelta al mundo existente, por un lado y los que apuestan quemar las naves e instan a la investigación y la aventura ${ }^{10}$. (PAVEL, 1991, p. 106) Esa isla que encierra todos los lenguajes pertenece a la segunda de las opciones: uno puede decidir ser un náufrago que se lanza a la aventura de desbordar una homogeneidad apócrifa, inventada por el discurso de la globalización.

es "solamente uno de los tres sistemas de comunicación [...]. Su lengua no es solamente extraña; también es simple y bien hecha, y tan bien hecha que revela mejor que la nuestra la naturaleza de las cosas. Lo extraño, es, pues, signo de superioridad." En la extrañeza de ese lenguaje reside también la crítica política de la utopía a los modos de representación de una sociedad. Crr. Buenos Aires: Hachette, 1986. p. 55-56.

9 Dice Piglia: "Los espías y los poetas escriben en una lengua cifrada. El más complejo de los sistemas de cifrado trabaja con permutaciones lineales del alfabeto (en lugar de $A$ pone $B$, en lugar de $C$ pone $D$ ). A menudo, sin embargo, estas modificaciones son arbitrarias". En esta frase resume la ficción de la isla y deja ver su política acerca de la literatura. Cfr "La cita privada" Crítica y ficción, op. Cit. 76.

10 Al respecto, una cita para completar: "Los márgenes, los territorios, los asentamientos de ficción, todo esto clama por viajeros metafóricos" 
Entonces surge esa posibilidad utópica de la que nos habla Bloch. Como el ángel de Klee, da vuelta la cabeza hacia el pasado y tiende la mano hacia el futuro. Buscar en el lenguaje lo que no está y alguna vez estuvo es también construir la posibilidad ontológica de lo real y desechar la absolutización ideológica del presente como un tiempo homogéneo y sólido.

\section{EL LIMONERO REAL: LA FICCIÓN DEL ORIGEN EN EL ESPEJO DE LA ISLA}

"Podemos por lo tanto afirmar que la verdad no es necesariamente lo contrario de la ficción, y cuando optamos por la práctica de la ficción no lo hacemos con el propósito turbio de tergiversar la verdad" dice Saer en El concepto de ficción. ${ }^{11}$ La tensión entre verdad y mentira se resuelve para Saer en la práctica de la ficción que posibilita la exploración de la realidad sin aprioris limitantes. (SAER, 1997, p. 12).

El limonero real (1979) construye la forma del relato en el intrincado ritmo de la repetición. Los nueve apartados de la novela no tiene otra marca que la reiteración rítmica, obsesiva y poética de un mismo fragmento descriptivo que juega en la repetición, la separación de los relatos. (Amanece/ Y ya está con los ojos abiertos).

Como una espiral dinámica la novela tiene un centro que revela su estrategia. La isla es la figura recurrente del espacio cuyo centro lo ocupa el limonero. Si el tiempo de la novela anula la continuidad, el espacio gira en círculos concéntricos. La isla es el lugar de los hombres, es el habitat del trabajo y el hogar, la isla se limita y define por el río. El río es el límite y la posibilidad, la salida y la clausura. Si un río tiene orillas, en las

1 Dice Saer en otro párrafo: "La paradoja propia de la ficción reside en que, si recurre a lo falso, lo hace para aumentar su credibilidad". 
orillas está el hombre, en el hombre, el relato, el recuerdo, la memoria. ("Entre las orillas, la franja estrecha del río era como una presencia espléndida pero sin vida" [...] En la orilla el río tenía algo de vida") Los relatos tiene el ritmo casi moroso del río y en esto no podemos dejar de reconocer la huella de Juanele (Juan L. Ortiz) donde el ritmo poético es el ritmo de un espacio que ha dejado de ser paisaje para ser todo: escritura, poeta, tiempo y origen..$^{12}$ La geografía que nos propone Saer es de un diseño diferente que no opone el continente a la isla sino el lugar real a la memoria y la imaginación. Algunos críticos han señalado que la novela anula el ritmo de la continuidad, pero desarrolla otro ritmo cíclico que se conjuga en un eje espacial: el limonero y un núcleo temporal: el 31 de diciembre. Como decíamos. el relato no avanza sino que - como señala Mirta Stern- borra, repite y se expande (SAER, 1981, p. I). Es en este punto que nos interesa detenernos: el ritmo de repetición y la figura de la isla. Este corregir, borrar y abrir del relato lleva al centro de una espiral que contiene el origen. En el apartado cinco, Wenceslao toma la voz del texto, el narrador en tercera desaparece, y cuenta, como el viajero que vuelve, no de otro espacio alternativo, sino del lugar originario de la memoria individual y colectiva. Cuenta y da cuenta de la creación, del mito fundante. El lugar es la isla.

12 Juanele señala "Habrás de saber, tú, que aisladamente, nada existe, pues, todo está en todo." Este gesto pánico de integración total entre el hombre y su lugar y entre el escritor y su escritura es el gesto que retoma Saer en el modo de narrar. La cadencia del río es uno de los ritmos que conjugan la armonía buscada. ("El río,/ y esas lilas que en él quedan.../ quedan.../ No se morirán esas lilas, no?. Saer lo sabe: "Es obvio que no se puede hablar de estos ríos sin evocar su figura y su poesía, que se confunde con ellos. "Cfr. Juan L. Ortiz Obra completa Entre Ríos: Universidad Nacional del Litoral, 1996, p. 751 y Juan José Saer "Sobre Juan L. Ortiz" en Poesía y Poética Número especial dedicado a Juan L. Ortiz, México: Universidad Iberoamericana, N 18, primavera 1995, p. 55-63. 
Utopía y mito se subsumen porque si la isla se transforma luego de la lluvia y la naturaleza benéfica habita ese lugar desolado y árido, el hombre ingresa luego y es su actividad organizativa la que transforma el espacio, ordena el caos de la naturaleza desbordante. Decíamos antes que la estrategia de la repetición resulta la clave para entender la forma del relato en esta novela. Wenceslao cuenta cómo la isla se le aparece cuando está en medio del río y cómo esa aparición se repite casi como una obsesión confundiendo la continuidad con la repetición. "Narrar es como nadar" decía Pavese. Si esto es así la analogía es perfecta para contar el origen:

"En eso, a unos veinte metros la misma islita. No otra, no vaya a creer, no, la misma, vea, igualita. La misma, únicamente que dos veces, una a unos veinte metros de la otra, chiquititas las dos, $\tan$ chiquititas que arriba de ellas no cabía más que uno solo, parado, derecho. La misma islita dos veces, pura agua alrededor, y después más nada. Más nada." (SAER, 1981, p. 123)

Wenceslao cuenta y vuelve a contar la aparición de la isla. Cada párrafo de su relato contiene cada secuencia de esa aparición, cada párrafo repite la escritura del anterior y agrega y corrige y expande. Si Wenceslao está absorto en esa repetición que anula la ilusión de continuidad y avance, el relato (la escritura de ese relato) contiene la misma estrategia. Repetición y diferencia, ritmo que conlleva en el dibujo de cada círculo, una pequeña marca, una fisura, "más nada" y es siempre una nada mayor. Una nada que hace tabla rasa e inventa el origen. De pronto, todas las imágenes diseminadas se unen y forman la única y primigenia y la isla se puebla de 
animales y vegetación. El movimiento de la repetición deja lugar al de la transformación. El juego de lo indiferenciado en las especies se establece en la mítica isla: cada planta puede dar lugar a una nueva especie en la conjugación de su ciclo.

En el espacio de la ficción, Saer puedenarrar el encuentro del mito con la utopía. El mundo de ficción que construye anula la temporalidad lineal y se centra en la productividad de la repetición, donde cada nota escanciada es la misma, y no lo es, hasta llegar al centro. "La verdadera génesis no se encuentra al principio sino al final y empezará a comenzar solo cuando la sociedad y la existencia se hagan radicales, es decir, cuando pongan en mano su raíz" dice Ernst (BLOCH 1977, p. 212). El gesto político de la ficción de Saer muestra esa génesis en la estrategia de ceder la voz: Wenceslao es el viajero que por esas rutas espiraladas vuelve del mito, vuelve de la utopía para contar. $Y$ cuenta las transformaciones de la isla, la intervención del hombre y el ordenamiento del caos. Aquella isla posible que aparecía y desaparecía se transforma en el lugar del hombre y allí la muerte es el hecho insólito que quiebra la cotidianeidad. La muerte lleva a la reflexión, a la filosofía. Pensar la muerte es una tarea que en la rudimentaria organización que Saer nos muestra ocupa un lugar social relevante. Ante la imposibilidad de que todos los hombres de la isla se dediquen a la tarea de descifrar el enigma del hombre que no despierta, surge, entonces, aquel que piensa por todos. La figura del intelectual en esa pequeña organización social tiene un lugar. Utopía realizada en el pasado, mito del origen que el rito de contar conserva. Como en Juanele, la clave está en perder la ciudad "para reencontrarlas sobre el vértigo, más puras en las relaciones de los orígenes".

Nos propusimos mostrar tres modelos abstractos que den cuenta de un mundo de ficción que encuentra, en la figura de la isla, su expresión más extrema. Elegimos las islas de Bioy, 
Piglia y Saer porque en ellas utopía y ficción se entrelazan de manera diferente y muestran diferentes formas de resignificar la tradición de la isla en la literatura. No nos quedamos tranquilos y conformes si, al menos, no mencionamos otras islas, otras ciudades utópicas, en definitiva, otros lugares imaginarios que pueblan nuestro territorio ficcional y a las que por razones de espacio no arribaremos. Girondo en Espantapájaros nos propone una ciudad "invadida por la certidumbre de la muerte" y Raúl González Tuñón nos habla "de una calle que hay en cualquier ciudad que nadie conoce ni transita". Marechal y el filósofo Schultze nos presentan a Cacodelphia como la contrafigura de la Buenos Aires visible; para Cortázar el país de los Cronopios es un lugar inaccesible que exige determinados y paródicos ritos burocráticos, y su isla al mediodía, que todos podemos ver desde el avión, nos promete un pasaje más fácil al mundo de la ficción. Los habitantes de Pajaritos, nos cuenta Belgrano Rawson, viven obsesionados con la posibilidad de ser enterrados vivos y en cierto Municipio la circulación de los techos por voladura se regula desde el Estado declara Macedonio Fernández, el viejo Recienvenido a la literatura, en sus Papeles. Daniel Moyano relata la resistencia de los músicos frente al sistema represivo de los Percusionistas en Hualacato. Los lugares de la ficción argentina arman un mapa posible que parece tener como presupuesto la frase de Tlön: "Quien siga ciertos rastros aparentemente casuales e indague en bibliotecas y librerías de viejo llegará a descubrir que la realidad de Tlön no es imaginaria". (BORGES, 1974, p.431) 
RESUMO: A literatura argentina possui grande diversidade de ilhas que fazem um mapa único da geografia da ficção e procuram conformar diferentes politicas na relação da ficção com a literatura y da literatura com a vida. Se a fiçño geográfica pode ser lida como uma construção conceptual que tece o possivel com o fictício, procuramos apresentar neste artigo, três modelos que mostram a relação entre ficção e utopia de jeito diferente, embora, em todos os casos, eles apostam a uma politica da literatura.

\section{REFERENCIAS}

BLOCH, E. El principio esperanza, t I II, Madrid: Aguilar, 1977 BORGES, Jorge Luis "Tlön, Uqbar, Orbis Tertius" en Ficciones, Obras Completas Buenos Aires: Emecé, 1974.

MOREAU, P., La utopía. Derecho natural y novela del Estado. Buenos Aires: Hachette. 1986.

PAVEL, Thomas Mundos de ficción. Caracas: Monte Avila. 1991.

PIGLIA, R. "La lectura de la ficción" en Crítica y ficción Buenos Aires: Siglo Veinte. 15

RUSSO, M y RIERA, D. "Entrevista a Bioy" La Maga. Homenaje a Bioy Edición Especial de Colección Número 19, abril de 1996.

SAER, J. J. El limonero real .Bs. As. : CEAL. 1981.

SAER.J. J. El concepto de ficción Buenos Aires: Ariel 1997. STERN Mirta Prólogo, El limonero real. Bs. As.: CEAL: 1981. 